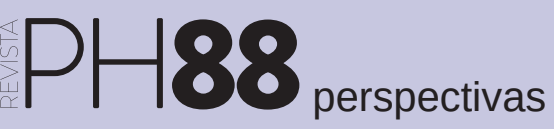

a debate La eficiencia energética y la edificación histórica | coordinan Mónica López Sánchez, Ana Yáñez Vega

\title{
Patrimonio o eficiencia energética en España: área protegida, área hipercarbónica
}

\author{
Rosana Caro Martínez | arquitecta, fundadora de Due south, arquitectura, patrimonio y eficiencia energética \\ URL de la contribución <www.iaph.es/revistaph/index.php/revistaph/article/view/3655>
}

Tres parecen haber sido las razones de que España escogiera excluir a los edificios protegidos del cumplimiento de las medidas de ahorro energético exigibles a los demás:

$>$ Representan un porcentaje bajo del total de los existentes.

$>$ Falta experiencia sobre los efectos que la rehabilitación energética acarrea en la salvaguarda de sus valores patrimoniales.

$>$ Exceso de celo en las normas que regulan sus intervenciones.

Dos podrán ser las consecuencias inmediatas:

$>$ Establecimiento de un dilema artificial sobre los edificios protegidos: o la salvaguarda de sus valores o su eficiencia energética, presuponiendo el dogma de su incompatibilidad sin analizar antes en qué casos ésta es real y en cuáles no tanto.

$>$ Conjuntos urbanos completos, ricos en edificios protegidos, quedarán condenados al despilfarro energético-económico o a la obsolescencia en materia de confort.

El primer error ha sido el trato homogéneo del heterogéneo conjunto de los edificios protegidos. Las categorías que los clasifican según la importancia de sus valores no surten efecto en cuanto a eficiencia energética.

El segundo ha sido afrontar la cuestión con una mirada sesgada que considera que cuando se mejoran energéticamente los edificios históricos protegidos, los únicos valores a preservar son estéticos e históricos, olvidando valores sociales y económicos que atañen fundamentalmente a sus usuarios.
Analicemos ahora cada una de las tres razones expuestas:

1. Los edificios protegidos son pocos.

Así es en el contexto global. Pero si acercamos la mirada desde la territorial estatal hasta la municipal, aumenta la proporción en el conjunto observado: no llegan al 1\% del total de los existentes en España pero suelen sobrepasar el $50 \%$ en muchas centros históricos ${ }^{1}$. Es el caso de Sevilla. Sus edificios catalogados se clasifican en cinco niveles (desde A hasta E) con grado de protección decreciente. Mayoritariamente catalogados en las categorías C, D y E, son de titularidad privada y uso residencial. En el barrio de la Magdalena, por ejemplo, el $67 \%$ de sus edificios están protegidos pero sólo el $2 \%$ con niveles altos ${ }^{2}$.

Es la iniciativa privada la que interviene en la mayor parte de ellos, según estrictos preceptos de rentabilidad económica y obligatoriedad, descartando habitualmente la inversión en ahorro energético, cuando el promotor de la obra no es quien lo va a explotar.

2. Parece complicado y no sabemos aún cómo hacerlo.

Nuestro Plan Nacional de Energía 2014-2020 considera que los edificios protegidos necesitan programas específicos para mejorar su eficiencia energética, pero no concreta cuáles. La incógnita se mantiene y éstos se rehabilitan bajo estándares energéticos menos exigentes que los no protegidos.

Sin embargo, técnicamente sí estamos preparados para afrontar la cuestión. Aunque los programas de simulación energética de homologación oficial no cuantifican el 


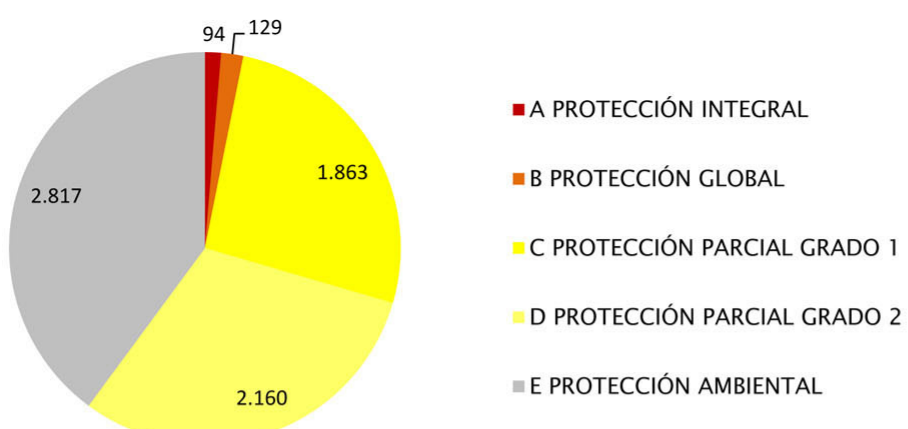

CLASIFICACIÓN Y NÚMERO DE EDIFICIOS PROTEGIDOS EN EL CONJUNTO HISTÓRICO DE SEVILLA Fuente: El Pais, 8 de abril de 1999

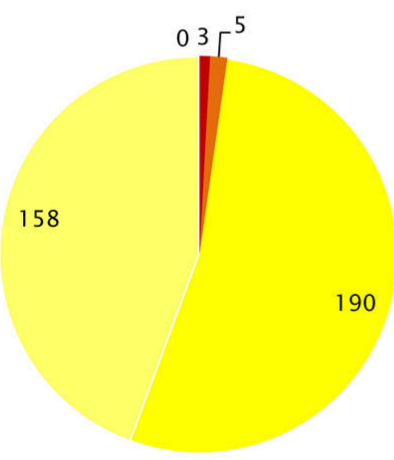

- A PROTECCIÓN INTEGRAL

- B PROTECCIÓN GLOBAL

- C PROTECCIÓN PARCIAL GRADO I

D PROTECCIÓN PARCIAL GRADO 2

=E PROTECCIÓN AMBIENTAL

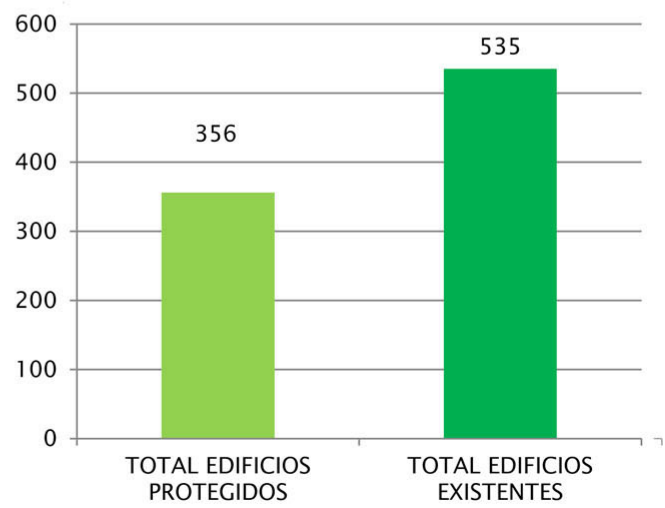

CLASIFICACIÓN Y NÚMERO DE EDIFICIOS PROTEGIDOS EN EL BARRIO DE LA MAGDALENA DE SEVILLA

Fuente: Elaboración propia a partir de los datos del Plan Especial de Protección del sector 8.4 La Magdalena

comportamiento real de elementos cruciales de nuestra arquitectura vernácula ${ }^{3}$ y asumen como ciertos algunos parámetros que frecuentemente no pueden aplicarse a los edificios antiguos ${ }^{4}$, es habitual entre los profesionales la utilización de modelos de simulación dinámica que se acercan más rigurosamente a la realidad y pueden justificar oficialmente las decisiones a tomar.

\section{Son edificios sagrados: el mito de la protección.}

Son numerosos los penosos ejemplos de cómo durante casi tres décadas (60-80) nuestros centros históricos sufrieron los embistes de la especulación urbanística y el rampante postmodernismo arquitectónico low-cost como guiño burlesco al pasado.

Por ello desde entonces, la protección de los edificios ha ido, con celeridad y creciente puritanismo, extendiéndose a la protección de los conjuntos en los que éstos se insertan. No se tutelan únicamente los monumentos sino un número mucho mayor de edificios cuyo interés radica en el grupo que contribuyen a conformar más que en los méritos individuales que intrínsecamente poseen ${ }^{5}$. El caso sevillano se repite frecuentemente en otras ciudades. Los edificios con nivel de protección blanda son la clase media de los edificios en los centros y en ellos 
se libra la verdadera batalla de la salud del casco histórico, de la que depende el estado general de salud de la ciudad.

Al calor del paradigma monumentalista-mercantilista imperante, nuestros cascos viejos se transmutan en evocaciones míticas espoleadas por la industria del turismo y entretenimiento del pensamiento globalizado, condenándolos a la obsolescencia y olvidando las verdaderas necesidades de sus poblaciones.

¿Qué tipo de desequilibrio estamos alimentando si avanzamos hacia centros caros hipercarbónicos y periferias asequibles limpias?

Los responsables de fijar los objetivos anticarbónicos europeos limitaron su mirada a la escala territorial. Sin duda, contabilizaron esta pequeña pérdida, este exceso de kilovatios sucios, estos edificios despilfarradores, pero no reflexionaron suficientemente sobre el destino social y económico de los barrios densos en protección, así definitivamente discriminados del resto.

\section{Qué paradoja: el área de impunidad es ahora el centro}

A corto plazo la solución proviene de los, por ahora, exiguos incentivos económicos a la rehabilitación sostenible, único instrumento capaz de insertar en la realidad de la rentabilidad económica los nuevos parámetros de eficiencia energética, lo que redundará en beneficio de los habitantes de los centros acarreando beneficios sociales derivados.

A medio plazo serán necesarios programas específicos fundamentados en la formación especializada de los profesionales involucrados. Algunos países, como Bélgica, ya han generado una especialización concreta llamada: Specialized energy consultancy for architectural heritage.

El enfoque de esta nueva formación, inexcusable y apremiante en la nueva era postcarbónica, merece ser completamente nuevo y desprejuiciado.
La protección garantista del patrimonio ha sido útil y necesaria como sobre-reacción a los atropellos cometidos. Pero ahora es indispensable una apuesta valiente por el futuro de los edificios viejos que conforman nuestra identidad cultural y a los que no podemos relegar a la desactualización en el contexto de sus funciones originales.

Las comisiones interdisciplinares responsables de interpretar las cautas normas que vienen rigiendo las intervenciones en patrimonio, al compás de los afectados por sus decisiones, deberán pertrecharse de nuevo armamento, explorar con mirada nueva las áreas de flexibilidad, pues existen.

\section{NOTAS}

1. URANGA, E. J.; ETXEPARE, L. (2014) Parque edificado o patrimonio edificado: la protección frente a la intervención energética. El caso del barrio de gros de San Sebastián. En LÓPEZ, M.; YÁÑEZ, A.; GOMES DA COSTA, S.; AVELLÀ, L., (coord.) Actas del Congreso Internacional de Eficiencia Energética y Edificación Histórica (Madrid, 29-30 Sep. 2014). Madrid: Fundación de Casas Históricas y Singulares y Fundación Ars Civilis, 2014.

2. De los 535 edificios existentes en el barrio de la Magdalena, 356 cuentan con algún tipo de protección. De éstos, solamente 8 están catalogados con niveles altos (A y B) de protección.

3. Las Ilamadas estrategias pasivas de ahorro energético, que la arquitectura vernácula de cada región ha ido seleccionando durante cientos de años, por ser las mejor adaptadas a las condiciones específicas, climatológicas, culturales y técnicas, de cada lugar.

4. Es el conocido caso de la asunción de que la temperatura operativa y temperatura seca del aire coinciden, válido solo para recintos con aislamiento térmico y donde la velocidad del aire no supera los 0.2 $\mathrm{m} / \mathrm{S}$; condiciones que no siempre se dan en los edificios del pasado.

\footnotetext{
5. Véase: Carta de Cracovia, 2000. Principios para la conservación y restauración del Patrimonio construido. Versión española del Instituto Español de Arquitectura (Universidad de Valladolid), Javier Rivera Blanco y Salvador Pérez Arroyo y The Paris Declaration, on Heritage as a driver of development. Paris, UNESCO, 2011. <http://www.international.icomos.org/Paris2011/GA2011_Declaration_de_Paris_EN_ 20120109.pdf>
} 